\title{
PENGUJIAN PROPERTIES LIMBAH TAILING KERING PADAT UNTUK PEMANFAATAN MATERIAL STABILISASI TANGGUL
}

\author{
Rakhmad Aji Prakosa
}

Maintenance \& Engineering Bureau, PT. Antam Tbk-UBPE Pongkor

\begin{abstract}
ABSTRAK
Hasil ekstraksi ore menjadi emas pada kegiatan pengolahan emas PT.Antam Tbk. - UBPE Pongkor, menghasilkan limbah hasil olahan berupa tailing yang dibuang ke TSF dalam bentuk slurry (20\%solid) kemudian diendapkan di beberapa kompartemen tampungan sebelum masuk ke Instalasi Pengolahan Air Limbah (IPAL). Tailing yang mengendap kemudian dikeruk dengan alat berat menuju area penimbusan akhir dengan kondisi Tailing 60\% solid. Semakin banyak tailing yang dihasilkan, maka semakin banyak juga upaya yang harus dilakukan untuk menyediakan tampungan tailing. Secara visual, tailing kering berbentuk seperti pasir, yang saat dalam kondisi padat memiliki daya dukung yang sangat baik untuk menahan beban diatasnya. Hal tersebut dibuktikan adanya dump truck dengan beban puluhan ton melintas diatas tailing kering padat sebagai pijakan tumpuannya tanpa mengalami failure. Dari kasus tersebut tailing kering dapat memungkinkan untuk dimanfaatkan sebagai material konstruksi tanggul, mengingat kemampuan daya dukungnya yang cukup baik saat dalam kondisi kering padat. Sehingga perlu dilakukan pengujian properties material tailing meliputi nilai kepadatan maksimumnya $\left(\mathrm{\gamma}_{\mathrm{d}}\right)$, berat jenis (BJ), nilai sudut geser dalam $(\phi)$, dan nilai kohesi (c).

Pengujian properties material tailing dilakukan dengan mengambil sampel terganggu (disturb) pada tailing dalam kondisi kering $( \pm 75 \%$ solid). Kemudian membuat sample remoulded dari tailing kering dan diperoleh nilai kepadatan tanah maksimumnya. Dari nilai kepadatan maksimum tersebut, dilakukan pengujian geser langsung untuk mengetahui nilai sudut geser dalam dan nilai kohesinya. Selain itu juga dilakukan uji piknometer untuk menghitung densitas tailing. Dari hasil parameter pengujian tersebut, kemudian dibandingkan dengan parameter timbunan tanah merah yang biasa digunakan sebagai material konstruksi tanggul dam dengan tujuan mensubstitusi material tanah merah dengan tailing. Hasil penelitian menunjukkan bahwa kepadatan maksimum tailing mencapai angka $1.65 \mathrm{gr} / \mathrm{cm}^{3}$, dengan kadar air optimum $15.2 \%$, kohesi $10 \mathrm{kPa}$, sudut geser internal $41^{\circ}$ dan koefisien permeabilitas $2.19 \times 10^{-4} \mathrm{~cm} / \mathrm{dt}$. Jika dibandingkan dengan properties material tanah merah yang biasa digunakan, memiliki kepadatan maksimum sebesar $1.68 \mathrm{gr} / \mathrm{cm}^{3}$, Kohesi $11.5 \mathrm{kPa}$, Sudut geser internal $29^{\circ}$, dan koefisien permeabilitas sebesar $7.7 \times 10^{-6} \mathrm{~cm} / \mathrm{dt}$ yang berarti nilai properties material tailing dan tanah relatif tidak berbeda jauh sehingga dapat dilakukan rekayasa engineering untuk memanfaatkan material tailing sebagai material konstruksi atau sebagai material stabilitas tanggul yang ada di area TSF.
\end{abstract}

Kata Kunci : Tailing, pemanfaatan limbah, material konstruksi

\section{ABSTRACT}

Ore extraction into gold at the gold processing activities of PT.Antam Tbk. - UBPE Pongkor, produces processed waste in the form of tailings which is discharged into TSF in the form of slurry (20\% solid) and then deposited in several storage compartments before entering the WastewaterTreatment Plant (IPAL). The deposited tailings are dredged with heavy equipment to the final landfill area with the condition of the tailings $60 \%$ solid. The more tailing produced, the more effort must be made to provide tailings storage. Visually, the dry tailings are shaped like sand, when it dense conditions has a very good capacity to distributing load. This case proof by the existence of dump trucks with tens of tons of load passing over the solid dry tailings as a foothold 
without failure. From these cases, dry tailings can be used as material for embankment construction, given their relatively good carrying capacity when in dense dry conditions. So that it is necessary to test the material properties of the tailings including its maximum density value ( $\mathrm{\gamma d}$ ), specific gravity $(B J)$, deep shear angle value $(\phi)$, and cohesion value (c). Testing the material properties of tailings is done by taking disturbed samples of the tailings in dry conditions $( \pm 75 \%$ solid). Then make a remoulded sample from dry tailings and get the maximum soil density value. From the maximum density value, then direct shear testing is performed to determine the value of the deep shear angle and its cohesion value. A pycnometer test was also conducted to calculate the tailing density. From the results of the test parameters, then compared with the parameters of the red soil heap which is commonly used as a dam construction material with the aim of substituting red soil material with tailings. The results showed that the maximum density of tailings reached 1.65 $\mathrm{gr} / \mathrm{cm} 3$, with an optimum moisture content of $15.2 \%$, cohesion of $10 \mathrm{kPa}$, internal shear angle of $41^{\circ}$ and permeability coefficient of $2.19 \times 10-4 \mathrm{~cm} / \mathrm{s}$. When compared with the properties of the commonly used red soil material, it has a maximum density of $1.68 \mathrm{gr} / \mathrm{cm} 3$, Cohesion of $11.5 \mathrm{kPa}$, an internal shear angle of $29^{\circ}$, and a permeability coefficient of $7.7 \times 10^{-6} \mathrm{~cm} /$ second which means the value of the material properties of the tailings and the soil is relatively not differ greatly so that engineering design can be carried out to utilize tailings as construction material or as a dike stability material in the TSF area.

Keywords : Tailing, Tailing Utilization, Construction Material

\section{A. PENDAHULUAN}

Proses penambangan bijih ore yang ditambang di tambang bawah tanah, diolah dan di ekstraksi untuk diambil emas dan peraknya (bullion). Hasil ekstraksi ore menjadi bullion pada kegiatan pengelolaan emas PT. Antam Tbk. - UBPE Pongkor, menghasilkan limbah hasil olahan berupa tailing yang dibuang ke TSF dalam bentuk slurry (20\% solid) kemudian diendapkan di beberapa kompartemen tampungan sebelum masuk ke Instalasi Pengeolaan Air Limbah (IPAL). Tailing yang mengendap kemudian dikeruk dengan alat berat menuju area penimbusan akhir dengan kondisi tailing $60 \%$ solid.

\section{A.1. Latar Belakang}

Semakin banyak tailing yang dihasilkan, maka semakin banyak juga upaya yang harus dilakukan untuk menyediakan tampungan tailing, mengingat tailing merupakan limbah dengan kategori limbah bahan beracun dan berbahaya (LB3). Secara visual, tailing kering berbentuk seperti pasir, yang saat dalam kondisi padat memiliki daya dukung yang sangat baik untuk menahan beban diatasnya. Hal tersebut dibuktikan adanya dump truck dengan beban puluhan ton dapat melintas diatas tailing kering padat sebagai pijakan tumpuannya tanpa mengalami failure (gambar 1).

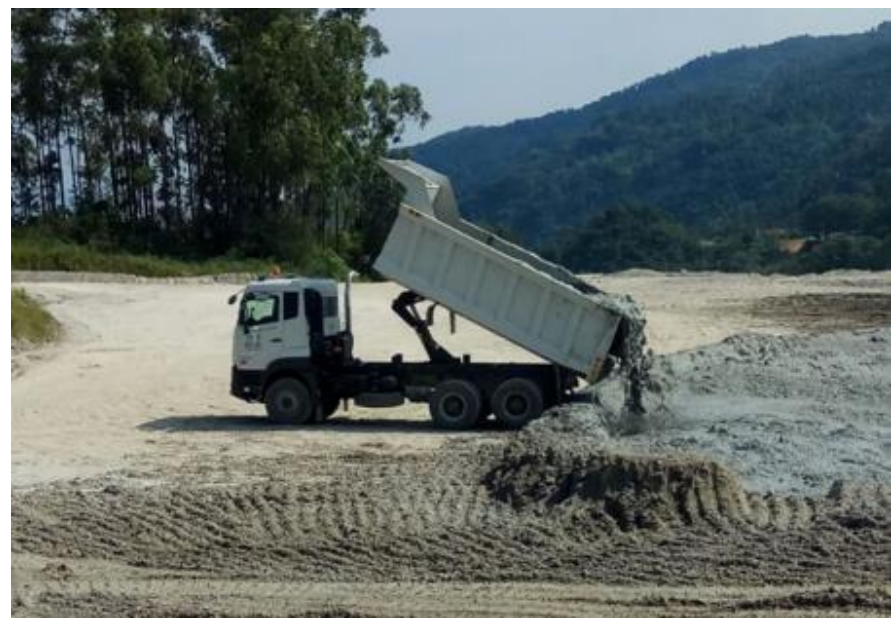


Gambar 1. Dump truk melakukan dumping lumpur di atas tailing kering.

\section{A.2. Tujuan}

Untuk mengetahui perbandingan antara karakteristik material konstruksi tanggul dam yang biasa digunakan (tanah merah) dengan karakteristik properties tailing. Tujuannya adalah sebagai material substitusi tanah merah dengan tailing kering, mengingat ketersediaan material tanah merah dalam jumlah terbatas sedangkan limbah tailing di area TSF sangat banyak dan terus tersedia selama operasional tambang terus berjalan.

\section{A.3. Pendekatan Pemecahan Masalah}

Tailing merupakan limbah hasil pengolahan tambang dengan kategori LB3 yang menjadi beban karena membutuhkan upaya yang cukup besar untuk menampungnya. Semakin banyak tailing yang dihasilkan, maka semakin besar juga upaya yang dibutuhkan. Untuk mengurangi upaya tersebut, penulis bermaksud akan melakukan pengujian properties tailing, dengan tujuan dapat melakukan substitusi material konstruksi tanggul dengan bahan limbah tailing. metode penelitian yang dilakukan pada penelitian ini meliputi studi literatur, studi lapangan, pengolahan data dan analisis.

\section{B. METODOLOGI PENELITIAN}

Penelitian ini dilakukan dengan sampel material terganggu (disturb) tanpa tambahan bahan material stabilisasi lainnya, melainkan hanya tailing kering yang diambil dalam kondisi $75 \%$ solid (kondisi kering lapangan) yang kemudian dibentuk (remoulded) dan dipadatkan dalam pengujian proctor untuk diketahui nilai kepadatan maksimumnya. Setelah diketahui nilai kepadatan maksimumnya, kemudian dilakukan pengujian nilai properties material dengan kepadatan maksimum pengujian proctor. Skema alur penelitian dapat dilihat pada gambar 2.

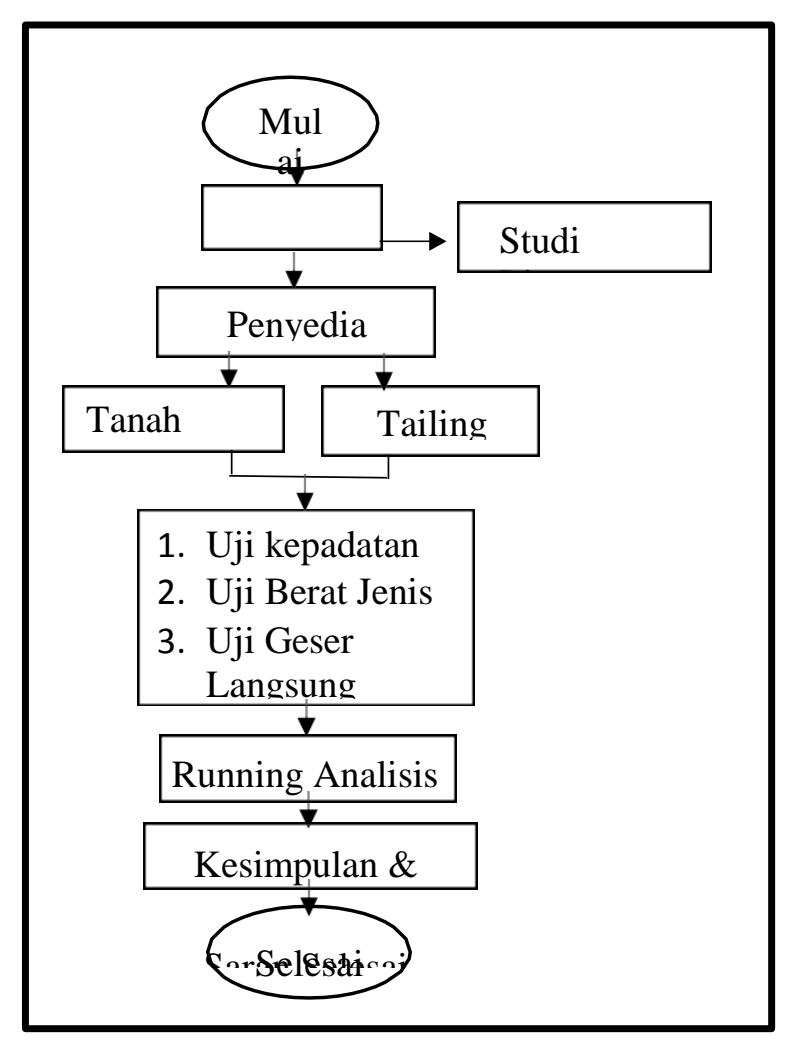

Gambar 2. Diagram alur penelitian 


\section{HASIL DAN PEMBAHASAN}

Mengacu pada alur pengujian gambar 2 tersebut, didapatlah nilai hasil properties pengujian material.

\section{C.1. Hasil Pengujian Material}

Pengujian material dimulai dari tahap pengambilan sampel material tailing kering kondisi tanah terganggu, kemudian dibentuk ulang (remoulded) dan dicari nilai kepadatan kering maksimum dengan uji proctor sebagai berikut ini.

Hasil pengujian kepadatan tailing kering, diperoleh kepadatan maksimum (yd maks) dengan kadar air optimum (Wopt) ditunjukkan pada tabel 1 berikut.

Tabel 1. Kepadatan maksimum terhadap kadar air optimum tailing

\begin{tabular}{|c|c|c|c|c|c|c|}
\hline \multirow{2}{*}{ No. } & \multirow{2}{*}{ Keterangan } & \multicolumn{5}{|c|}{ No Sampel } \\
\hline & & 1 & 2 & 3 & 4 & 5 \\
\hline 1 & Berat Volume Basah, $\mathrm{g} / \mathrm{cm}^{3}$ & 1.67 & 1.77 & 1.86 & 1.93 & 1.84 \\
\hline 2 & Kadar Air $(\%)$ & 5.11 & 9.23 & 12.9 & 18.67 & 22.24 \\
\hline 3 & Berat Volume Kering, g/cm ${ }^{3}$ & 1.59 & 1.63 & 1.65 & 1.63 & 1.51 \\
\hline
\end{tabular}

Dari hasil pemadatan tanah 5 sampel uji tersebut, kepadatan maksimum ( $\mathrm{yd}$ maks) yang diperoleh dari perhitungan berat volume basah ( $\mathrm{yb}$ ) dibagi terhadap 100\% ditambah kadar air dalam persen, dan didapat nilai kepadatan maksimum terbesar ( $\mathrm{yd}$ maks) yaitu pada sampel 3 dengan nilai 1.65 $\mathrm{g} / \mathrm{cm}^{3}$. Kurva kepadatan maksimum dapat dilihat pada gambar 3 .

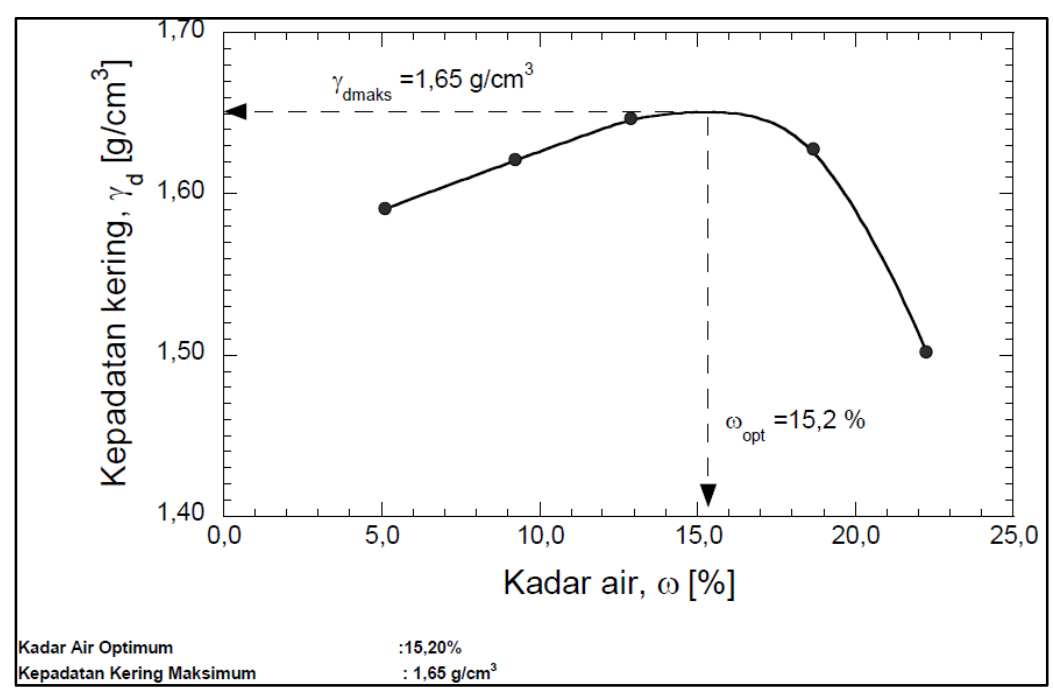

Gambar 3. Kurva pemadatan tailing.

Setelah diperoleh nilai kepadatan maksimum uji proktor, kemudian dilanjutkan dengan melakukan uji geser langsung yang dilakukan dengan acuan hasil uji pemadatan proktor (tabel 1) yaitu saat tailing mencapai nilai kepadatan kering maksimum sebesar $1.65 \mathrm{gr} / \mathrm{cm}^{3}$. Dari acuan nilai tersebut, kemudian dilakukan pengujian geser langsung dan dihasilkan nilai properties material tailing dengan nilai kohesi sebesar $10.384 \mathrm{kPa}$ dan sudut gesek internal sebesar $38.97^{\circ}$ Selain itu, dengan kepadatan tersebut juga dijadikan acuan untuk uji permeabilitas material dan didapatkan nilai permeabilitas $\mathrm{k}_{20}$ sebesar $2.19 \times 10^{-4} \mathrm{~cm} / \mathrm{dt}$. Selanjutnya dilakukan uji properties lainnya seperti uji kerapatan massa Gs dengan nilai sebesar 2.53. 
Hasil nilai dari pengujian material tailing kering dalam kondisi padat maksimum $1.65 \mathrm{gr} / \mathrm{cm}^{3}$ dapat dirangkum pada tabel 2 sebagai berikut.

Tabel 2. Resume pengujian properties tailing

\begin{tabular}{|c|c|c|c|c|}
\hline No. & Keterangan & Notasi & Nilai & Satuan \\
\hline \multirow[t]{3}{*}{1} & Uji Kepadatan & & & \\
\hline & Kepadatan kering maksimum & $\gamma_{\text {dmaks }}$ & $\begin{array}{c}1.65 \\
16.19\end{array}$ & $\begin{array}{l}\mathrm{gr} / \mathrm{cm}^{3} \\
\mathrm{kN} / \mathrm{m} 3\end{array}$ \\
\hline & Kadar air optimum & w & 15.2 & $\%$ \\
\hline 2 & Uji Berat Jenis & Gs & 2.53 & \\
\hline \multirow[t]{3}{*}{3} & Uji Geser Langsung & & & \\
\hline & Kohesi & $\mathrm{C}$ & 10.384 & $\mathrm{kPa}$ \\
\hline & Sudut gesek internal & $\varnothing$ & 38.97 & $\mathrm{o}$ \\
\hline 4 & Uji Permeabilitas & $\mathrm{k}_{20}$ & $2.19 \times 10^{-4}$ & $\mathrm{~cm} / \mathrm{dt}$ \\
\hline
\end{tabular}

Dari resume pengujian properties tailing tersebut, kemudian dibandingkan dengan hasil pengujian properties material tanah merah. Hasil pengujian properties tanah merah dan material konstruksi tanggul dirangkum pada tabel 3 sebagai berikut ini.

Tabel 3. Hasil properties material konstruksi tanggul

\begin{tabular}{|c|c|c|c|c|c|c|c|}
\hline No. & Keterangan & $\begin{array}{c}\gamma_{\mathrm{m}} \\
\mathrm{kN} / \mathrm{m}^{3}\end{array}$ & $\begin{array}{c}\mathrm{c} \\
\mathrm{kN} / \mathrm{m}^{2}\end{array}$ & $\begin{array}{c}\mathrm{c}^{\prime} \\
\mathrm{kN} / \mathrm{m}^{2}\end{array}$ & $\varnothing$ & $\varnothing^{\prime}$ & $\begin{array}{l}\text { Permeabilitas } \\
\quad(\mathrm{cm} / \mathrm{det})\end{array}$ \\
\hline 1 & Tanah Clay (Tanah Merah) & 16.5 & 28 & 36 & 16.5 & 13 & $2.1 \times 10^{-7}$ \\
\hline 2 & Filter/ Sand Layer & 18.05 & 0 & 0 & 30 & 30 & $1.0 \times 10^{-3}$ \\
\hline 3 & Rockfill / Batu & 20 & 0 & 0 & 45 & 45 & $1.0 \times 10^{-1}$ \\
\hline 4 & Tailing sedimen (basah) & 16.5 & 0 & 0 & 13.5 & 0 & $2.19 \times 10^{-4}$ \\
\hline
\end{tabular}

Pada perhitungan nilai tahanan geser material, nilai tegangan geser sesuai pada persamaan 1 berikut ini.

$$
\tau=\mathrm{c}+\sigma \tan \varnothing
$$

Keterangan :

$\tau=$ nilai tahanan geser material

$\mathrm{c}=$ kohesi material

$\varnothing=$ sudut gesek internal

Semakin besar nilai c dan $\varnothing$ dari material, maka akan semakin besar juga tahanan geser material tersebut, yang berarti material tersebut memiliki tahanan geser yang cukup baik dalam menahan tegangan hingga mengalami failure. Apabila digambarkan pada grafik mohr coulomb, maka akan didapatkan grafik selubung kegagalan mohr colomb seperti Gambar 4 berikut.

Menunjukkan bahwa material tanah dengan tegangan awal $\sigma 3$ akan mengalami keruntuhan jika diberi tegangan hingga $\sigma 1$ dengan persamaan fungsi $\tau=c+\sigma \tan \varnothing$. Dengan adanya nilai sudut gesek internal dan kohesi yang besar, memungkinkan material untuk menerima tegangan lebih besar lagi hingga akhirnya mengalami runtuh. 


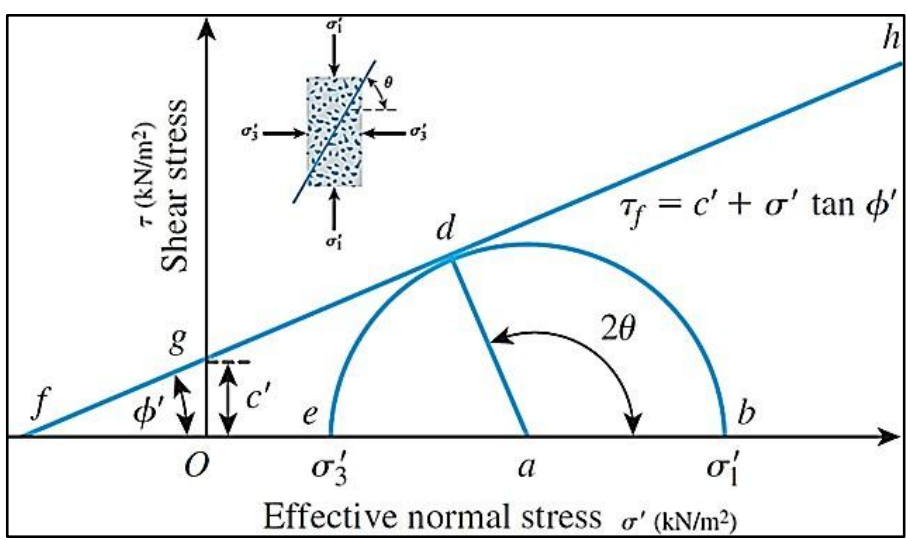

Gambar 4. Selubung kegagalan mohr coulomb

Selain memiliki nilai $\mathrm{c}$ dan $\varnothing$, material tailing juga memiliki berat jenis material yang cukup tinggi yaitu sebesar $1.65 \mathrm{gr} / \mathrm{cm}^{3}$, hanya selisih sedikit dibandingkan material tanah merah dengan berat jenis sebesar $1.69 \mathrm{gr} / \mathrm{cm}^{3}$. Semakin berat material, maka akan semakin stabil dalam menahan gaya horizontal.

\section{C.2. Simulasi Running Geoslope}

Adanya nilai c, $\varnothing$ dan berat jenis material tailing, dapat digunakan sebagai bahan input material untuk simulasi stabilitas tanggul dengan bantuan program geostudio slope/w. Sebagai studi kasus, penulis melakukan kajian simulasi di lokasi tanggul dam lahan A.

Dalam kasus ini, penulis mencoba membandingkan hasil simulasi stabilitas lereng dengan material konstruksi tanah merah terhadap material konstruksi tailing. Dari hasil simulasi tersebut (gambar 5), didapatkan nilai faktor keamanan lereng sebesar 1.215 (dengan koefisien beban gempa horizontal 0.3).

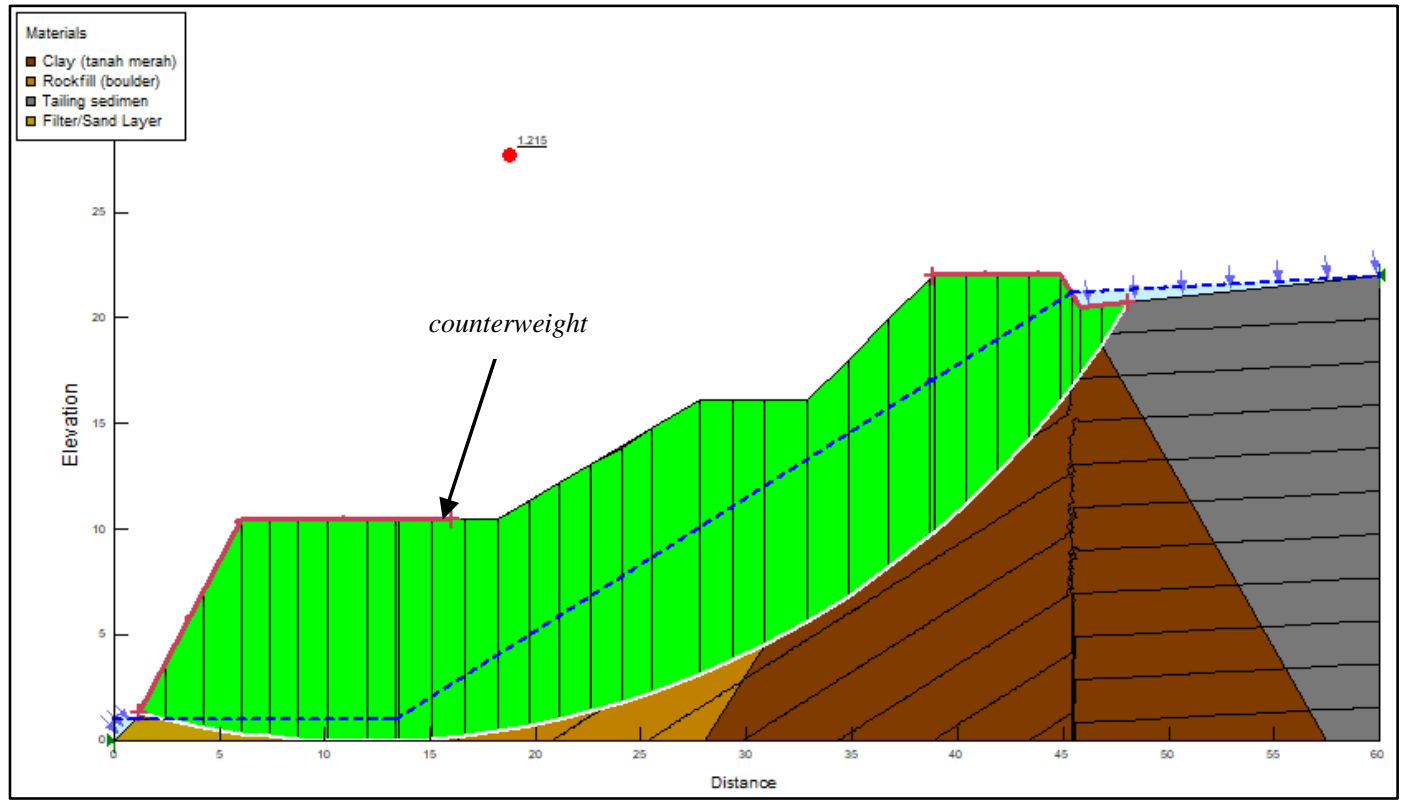

Gambar 5. Simulasi tanggul dam Lahan A dengan material tanah merah pada counterweight. 
Sedangkan untuk simulasi tanggul dam Lahan A dengan material tailing kering sebagai material pengganti tanah merah pada counterweight. Dari hasil simulasi tersebut (Gambar 6), didapatkan nilai faktor keamanan lereng sebesar 1.199 (termasuk koefisien beban gempa horizontal 0.3).

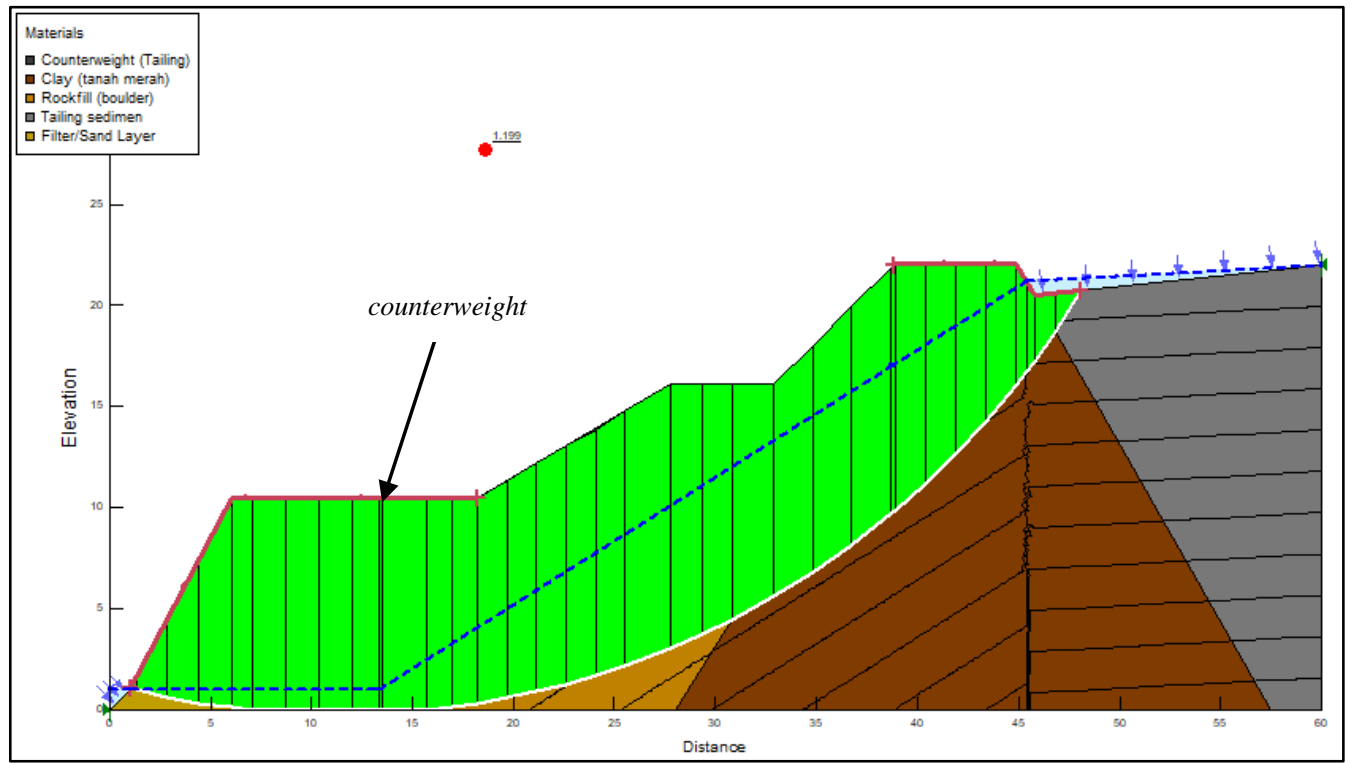

Gambar 6. Simulasi tanggul dam Lahan A dengan tailing kering pada counterweight.

\section{PEMBAHASAN}

Dari hasil pengujian tersebut, terlihat tailing dengan kepadatan maksimum ( $\mathrm{\gamma d}$ maks ) memiliki kekuatan properties material yang cukup besar yang dibutktikan dengan tingginya nilai c dan $\varnothing$. Nilai $\varnothing$ pada tailing bahkan lebih besar daripada nilai $\varnothing$ pada material tanah merah.

Dari perbandingan kedua simulasi tersebut, nampak bahwa penggunaan material tailing sebagai stabilisasi tanggul dam (digunakan pada bagian counterweight) memiliki stabilitas lereng yang sama baiknya dengan ditunjukkan bahwa nilai Factor Safety hanya berselisih 0.016 lebih kecil daripada material dengan tanah merah. Selain itu, ketersediaan tailing yang sangat banyak tentu akan memudahkan dan mengurangi upaya dalam penyediaan kapasitas tampung limbah tailing dibanding harus mencari material konstruksi tanah merah.

Akan tetapi perlu ditinjau dari sisi lain yaitu tingginya nilai permeabilitas tailing sebesar $2.19 \times 10^{-4}$ dibandingkan material tanah merah sebesar $2.1 \times 10^{-7}$, yang berarti material tanah merah lebih kedap air sehingga dapat menjaga kondisi konstruksi tanggul dalam keadaan kering saat terjadi hujan, maupun menahan rembesan air, sehingga perlu rekayasa engineering lainnya untuk meningkatkan nilai kekedapan air pada material tailing.

\section{E. KESIMPULAN}

Dari uraian latar belakang, hasil pengujian hingga pembahasan tersebut, didapatkan suatu kesimpulan bahwa:

a. Tailing memiliki parameter $\mathrm{c}$ dan $\varnothing$ yang cukup besar sehingga memiliki stabilitas cukup baik dalam kondisi padat.

b. Hasil simulasi stabilitas tanggul antara material tanah merah dengan material tailing saat digunakan sebagai konstruksi counterweight sama baiknya dengan selisih safety factor 
sebesar 0.016 .

c. Ketersediaan tailing yang cukup banyak menjadikan ketersediaan dan perolehan material lebih baik dan lebih mudah daripada material konstruksi tanah merah, sehingga diperoleh efisiensi lebih baik.

d. Tailing memiliki kelemahan nilai permeabilitas yang cukup tinggi, sehingga memerlukan rekayasa engineering yang baik untuk digunakan sebagai material konstruksi tanggul dam agar tanggul dam tahan terhadap air hujan maupun rembesan air.

\section{DAFTAR PUSTAKA}

Cindarto. (2018). Laporan Tri Wulan Pemantauan Bendungan TSF. Bandung: PT CND. Das, B. M. (2011). Principles of Foundation Engineering. Washington: Global Engineering.

Das, B. M. (2014). Advanced Soil Mechanics. 6000 Broken Sound Parkway NW, Suite 300: CRC Press.

Hardiyatmo, H. C. (2017). Mekanika Tanah II. Yogyakarta: UGM Press. 